\title{
BIM-based mixed-reality application for bridge inspection and maintenance
}

\author{
Duy-Cuong Nguyen \\ Chung-Ang University, South Korea \\ The Quan Nguyen \\ National University of Civil Engineering, Vietnam \\ Ruoyu Jin \\ London South Bank University, United Kingdom \\ Chi Ho Jeon, Chang Su Shim* \\ Chung-Ang University, South Korea
}

\begin{abstract}
Purpose - The purpose of this study is to develop a BIM-based mixed reality (MR) application to enhance and facilitate the process of managing bridge inspection and maintenance works remotely from office. It aims to address the ineffective decision-making process on maintenance tasks from the conventional method which relies on documents and $2 \mathrm{D}$ drawings on visual inspection. This study targets two key issues: creating a BIM-based model for bridge inspection and maintenance; and developing this model in a MR platform based on Microsoft Hololens.
\end{abstract}

Design/methodology/approach - Literature review is conducted to determine the limitation of MR technology in the construction industry and identify the gaps of integration of BIM and MR for bridge inspection works. A new framework for a greater adoption of integrated BIM and Hololens is proposed. It consists of a bridge information model for inspection and a newly-developed Hololens application named "HoloBridge". This application contains the functional modules that allow users to check and update the progress of inspection and maintenance. The application has been implemented for an existing bridge in South Korea as the case study.

Findings - The results from pilot implementation show that the inspection information management can be enhanced because the inspection database can be systematically captured, stored and managed through BIM-based models. The inspection information in MR environment has been improved in interpretation, visualization and visual interpretation of 3D models because of intuitively interactive in real-time simulation.

Originality/value - The proposed framework through "HoloBridge" application explores the potential of integrating BIM and MR technology by using Hololens. It provides new possibilities for remote inspection of bridge conditions.

Keywords: Mixed reality, Building Information Modelling (BIM), Hololens, bridge inspection, bridge maintenance, integrated BIM and mixed reality

Paper type Research paper

\section{Introduction}

In the era of construction 4.0 revolution, promising technologies such as Building Information Modelling (BIM), virtual reality (VR), augmented reality (AR) and mixed reality (MR) promote digitisation and automation in information management and visualization. In recent years, MR is being adopted as an innovation for project information interaction and collaboration among stakeholders (Dunston and Wang, 2005). It enables enhanced data accessibility for better understanding of project data to make better 
decisions in project management such as design check, construction simulation, and monitoring. Since BIM adoption becomes popular in the construction sector, the use of BIM-based systems has been proven as an effective solution for project information management based on a 3D model working environment (Demian and Walters, 2014). Therefore, an integration of MR and BIM technology can create a novel and powerful application for project information management.

MR presents the reality-virtuality continuum, which is the process of blending the 3D project model in real-world representation based on computing technologies. MR combines the features of both VR and AR. VR environment provides a computer-generated reality wherein the user can completely immerse and interact with model objects using a VR headset. Rather than fully immersive in a virtual environment, AR enhances model interaction between the virtual and the real worlds via smartphones, tablets, and AR glasses. According to Rokhsaritalemi (2020), three main characters of MR are immersion, interaction and information. Immersion refers to the act of a user completely immersing oneself into the virtual world by real-time interaction. In the MR environment, the user interacts with the object to access information by natural communication modes such as gestures, voice, and gaze. However, the development of MR faces two significant challenges, namely display technology and tracking. MR application needs to display the output model with high resolution and contrast. The interaction between virtual models with the user's command requires precise and fast methods. Immersive technologies such as VR, AR, MR have been applied in the construction industry for remote managing the project (Elghaish et al., 2020; Davidson et al., 2020). There are project control and monitoring, defect and quality management, team collaboration, construction education, and quantity take-off. For MR-based application development, Microsoft Hololens has been introduced as the most prominent MR device. Microsoft Hololens is the first self-contained holographic computer that allows users to engage with 3D digital content and interact with holograms in a hybrid reality. In recent years, the MR-based application from BIM using Microsoft Hololens has been developed in the field of Architecture, Engineering and Construction (AEC). An AEC project usually contains a huge amount of information that requires access from various stakeholders such as the contractor, owner, and consultant. Hololens enables information sharing among different stakeholders based on BIM in holographic environments and improves collaboration, coordination, and understanding of project documents (Hamzeh et al., 2019. Furthermore, a BIM-based construction project enables the integration of operational data with the 3D model to enhance the efficiency of on-site activities (Sheikhkhoshkar et al., 2019).

In modern infrastructure development, bridges are the most expensive and complex structures. Therefore, the transportation agency needs to have an innovative application for improving inspection and maintenance tasks. An appropriate maintenance planning can minimize the maintenance and repair expenses in the bridge life cycle (Nili et al., 2021). Bridge inspection is the process of determining the physical and functional conditions of its structures. It is the main task of bridge monitoring and maintaining work, which provides the safety assessment and condition document for the bridge asset management system. Ground-penetrating radar (GPR), close-range photogrammetry (CRP), and terrestrial laser scanning (TLS) are common non-contact testing (NCT) technologies, which have been widely used for bridge condition monitoring (Dabous et al., 2020). Recently, artificial intelligence (AI) and deep learning (DL) has been widely used in visual inspection to detect the damages such as crack, spalling automatically (Mansuri and Patel 2021; Abdelkader 2021). During the bridge operation phase, the inspection work includes the general inspection, principal inspection, and special inspection by various inspection methods and technologies. A huge amount of inspection data is hence generated. An inefficient information management system leads to time-consuming safety assessment for maintenance works. A major limitation of monitoring the deterioration process is the lack of digitalized damage records to compare the current inspection result with the previous conditions. It requires a single-source data model, which can systematically manage the inspection database and new visualization technology for better understanding the massive and complex inspection information. To solve this problem, this study introduces a BIM-based MR application named "HoloBridge" to enhance and facilitate the process of bridge inspection and management of maintenance works remotely. The novel features of this application are based on the advance of information management in a BIM-based system and data visualization in the MR platform. The pilot implementation for an existing bridge is adopted to 
demonstrate how the BIM-based inspection model in the MR environment can support better understanding of inspection data for making more reliable decisions on maintenance tasks.

\section{Literature review}

Mixed-reality (MR) applications have been widely adopted in the design, construction, operation phase for leveraging data visualization, communication, and collaboration based on BIM. In the design process, some studies address the impact of MR on the virtual representation of BIM objects to improve design productivity and quality (Chalhoub and Ayer, 2018; Prabhakaran et al., 2020). Most Hololens users have found that MR supports easier understanding of the complex design and reduces errors during the construction process as compared to the approach of using 3D BIM and paper documents. In the construction phase, BIM-based models can be visualized through Hololens to overlay on the construction site with exact scale for comparison between design and actual work (Al-Adhami et al., 2019; Feng and Chen, 2019). Therefore, the quality of on-site inspection work has been enhanced by the BIM-MR inspection system. Moreover, 4D BIM scheduling and sequencing can also be shown in the MR environment (Riexinger et al., 2018). El Ammari and Hammad (2019) proposed a BIM-based MR approach for facilities management in the operation phase. This application allows users to visualize inspection and maintenance information support for remote collaboration between on-site inspection and management work remotely. The BIM software developers such as Trimble and Bentley have developed BIM-based MR applications to explore the full potential of BIM itself in the MR space. Table 1 provides the list of commercial MR applications from BIM developers. Information in BIM can be directly transferred to Hololens through these applications. While MR application developers have addressed the visualization of 3D models, the use of the BIM database has not been well established in MR working space. There is a lack of robust research on the systematic delivery of BIM databases to MR applications. The BIM database throughout the project lifecycle can be more effectively managed in MR environment.

\begin{tabular}{llll}
\hline Applications & Main functions & Developers & Web links \\
\hline Synchro XR & $\begin{array}{l}\text { Visualizing 4D } \\
\text { construction digital twins }\end{array}$ & Bentley & $\underline{\text { https://www.bentley.com/ }}$ \\
& $\begin{array}{l}\text { Viewing, interact, and } \\
\text { collaborate BIM model in } \\
\text { job site }\end{array}$ & VisualLive & $\underline{\text { https://visuallive.com/ }}$ \\
& $\begin{array}{l}\text { Reviewing BIM models, } \\
\text { coordinate projects, } \\
\text { manage sequencing and } \\
\text { monitor progress }\end{array}$ & BIM Holoview & $\underline{\text { http://www.bimholoview.com/ }}$ \\
BIM Holoview & $\begin{array}{l}\text { Enabling review of BIM } \\
\text { models overlaid in the job } \\
\text { site }\end{array}$ & Trimble & \\
Trimble & $\begin{array}{l}\text { Viewing and simulating } \\
\text { Connect }\end{array}$ & hD sequence, multi-user & Kalloc Studios $/ /$ mixedreality.trimble.com/ \\
Fuzor AR & Hololens collaboration & $\underline{h t p s: / / w w w . k a l l o c t e c h . c o m / ~}$ \\
\hline
\end{tabular}

Table 1: The commercial BIM-base MR application

Bridge information model (BrIM) is an integrated BIM model for improving bridge information collaboration and management throughout the project lifecycle, from planning to maintenance (Shim et al., 2012). BrIM includes a three-dimensional (3D) bridge model and a systematic database. BIM-based systems have been implemented to facilitate enhanced bridge inspection and maintenance processes (McGuire et al., 2016; Shim et al., 2017). The advanced feature of BIM is the facilitation of data exchange, integration, and interoperability in digital formats during the project lifecycle (Eastman et al., 
2011). For inspection work, the defect information is extracted and modelled to overlap with BIM element model (Hüthwohl et al., 2018; Sacks et al., 2018). The prototypical implementation has proven the possibility of integrating inspection data with a 3D model to create a BIM-based inspection platform. Moreover, the BIM-based inspection model can also minimize errors of inspectors' evaluation and reduce the time by using 3D model visualization for better understanding bridge structure (Al-Shalabi et al., 2015).

Using Microsoft Hololens with MR application is the next generation of bridge inspection (Mascareñas et al., 2020). Hololens is a wearable device that can be used to inspect bridges in the field and office. Hololens applications have been developed for onsite bridge inspection (Karaaslan et al., 2019; Moreu et al., 2017). Users can automatically detect some types of defects such as cracking and spalling with dimension information in real-time by Hololens. Besides, AR technology has been investigated and applied in bridge inspection works (Salamak and Januszka, 2018). However, only onsite inspection work has been the focal point of existing studies. Limited research on using Hololens application for remote bridge inspection has been available. Omer et al., (2019) developed a VR application to move bridge inspection work from onsite to the office. The application enables users to use a VR device to walk in a virtual environment (i.e., a bridge virtual model developed from 3D scanned data) to check the bridge structures' condition. However, this application has a limitation that a new model needs to be developed from scanned data each time. The system has no mechanism to update the existing model with newly scanned data for inspection due to the lack of a single inspection database system. Recently, a welldefined database for storing, updating and managing BIM-based bridge inspection data has been developed and tested in a study by Shim et al. (2017). The idea of developing and managing this type of database could be integrated in a BIM-based MR application in order to well explore the updated data for enabling and facilitating remote inspection and maintenance of bridges.

\section{Methodology}

Aiming to develop a novel BIM-based MR application for enhancing and facilitating off-site bridge inspection and maintenance management, this study applied a combination of research methods. Literature review was conducted to discover the limitation of existing BIM-based MR applications and also the challenges in developing and managing a proper database that can be updated with scanned data from fieldwork. A trial and error method was used to develop a framework for integrating a BrIM model and a new MR-based application which has been developed to facilitate inspection and maintenance management of bridges. The BrIM model was established using parametric modelling. It played as a central database for systematic integration of inspection and maintenance management. The MR-based application, named "HoloBridge", was developed through a cross-game engine platform incorporating BIM. HoloBridge was used to exploit the database integrated in the BrIM model for better data processing to support decision making processes regarding inspection and maintenance work. The framework was tested in a case study bridge for validation and improvement.

\subsection{The developed framework}

The developed research framework for bridge inspection and maintenance is shown in Figure 1. This framework has four major components: (I) Data acquisition, (II) Data processing, (III) BIM-based system, and (IV) MR-based inspection. Aiming to develop the BIM-based MR application, this study does not discuss in details of components I and II, which are the data preparation process to establish a BIM-based inspection and maintenance system, but focuses on the BIM-based system for bridge inspection and MR-based inspection process.

Data acquisition is the process of gathering inspection data from different inspection levels such as general, principal, and special inspections by modern bridge inspection technologies. For visual inspection, a drone is used to simplify complex inspection tasks with high-quality photos and videos. The drone data provides a database to generate a 3D bridge scanned model enabled by photogrammetry techniques. The 3D scanned model provides geometric data with defects visualization. Besides, GPR 
method is used to capture the concrete and pavement subsurface for detecting damages such as delamination and voids. The inspection documentation is generated with the detailed damage information involving damage detection, classification, and measurement in data processing. The BIMbased system consists of two major components: the 3D bridge information authoring and the database developed at the data processing stage. The 3D bridge structure model is created with the corresponding inventory system. Each bridge element model contains model attributes, archive data, and a link to the inspection database. Finally, the HoloBridge application is developed from a cross-platform game engine and BIM models. The application brings the $3 \mathrm{D}$ bridge model to the real-world and allows users to query the inspection database to check and monitor the structural condition. Then, users can evaluate the damage development progress over time by the damage mapping algorithm and make a more reliable decision for maintenance works.

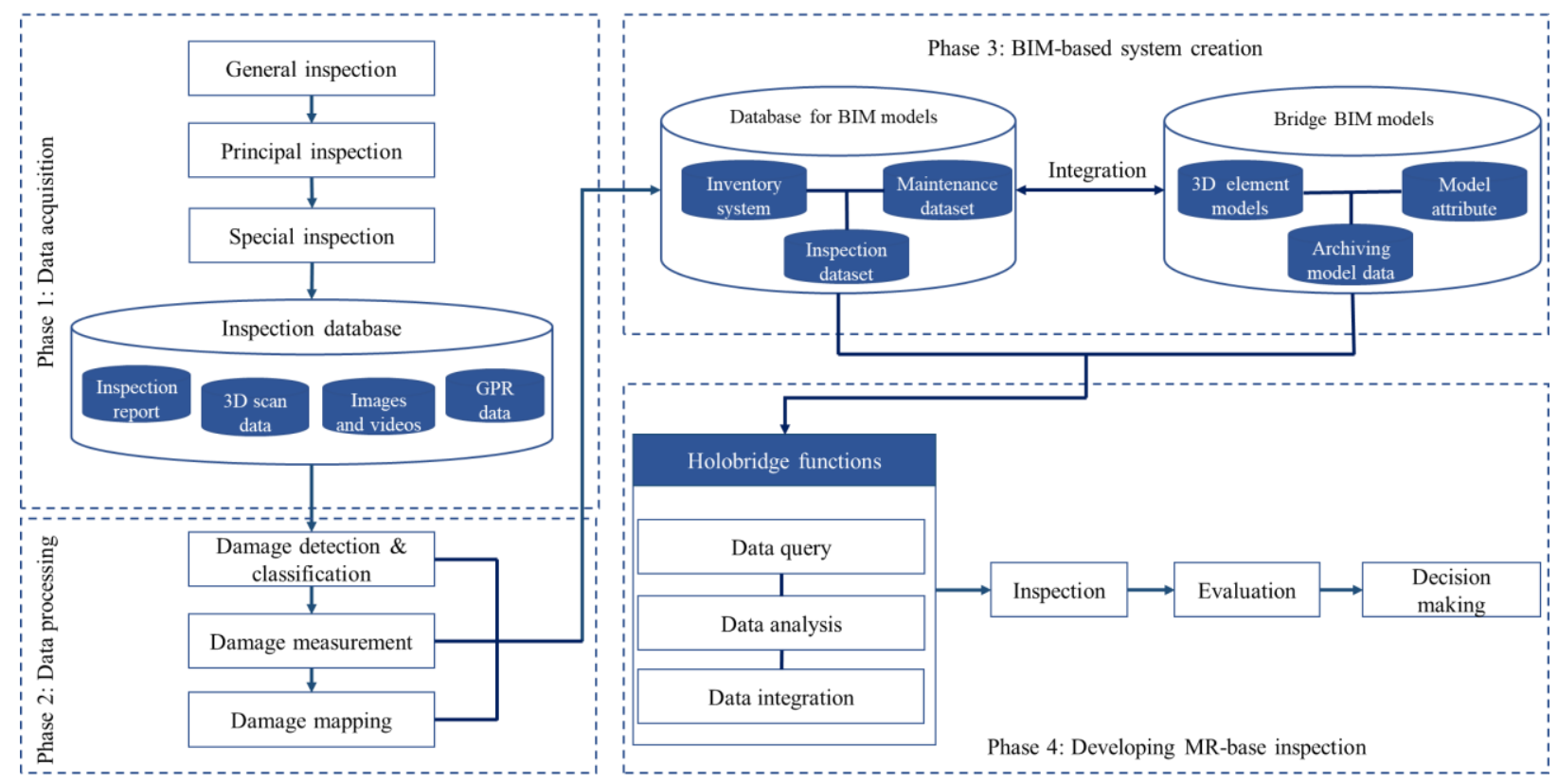

Figure 1. The developed framework

\subsection{Application development workflow}

Figure 2 presents the development workflow of the HoloBridge application. The workflow consists of three primary layers: BIM modeling development, application development, and application compilation. The first layer is the development of the 3D model of the asset using Revit and Dynamo from bridge geometric information. The model was then exported to an exchangeable 3D format such as IFC (industry foundation class), FBX (Autodesk Filmbox format) to be imported into the application. The second layer, application development is comprised of the user interface design and the development of functional modules uses C\# programming language in Unity 2019.3. Major modules are programmed to perform the tasks of inspection, evaluation, cloud-based documentation, and damage mapping. Inspection modules have several valuable functions to visualize the inspection report and damage location along with damage profiles. The monitoring function integrates an algorithm to overlap damaged data in the element model over time. The cloud-based platform allows users to access documents from cloud storage. The evaluation module emphasizes the rating system from the colour scheme. Consequently, maintenance actions can be planned. The last layer is application complier, where the application is deployed to Hololens by Microsoft Visual Studio. 


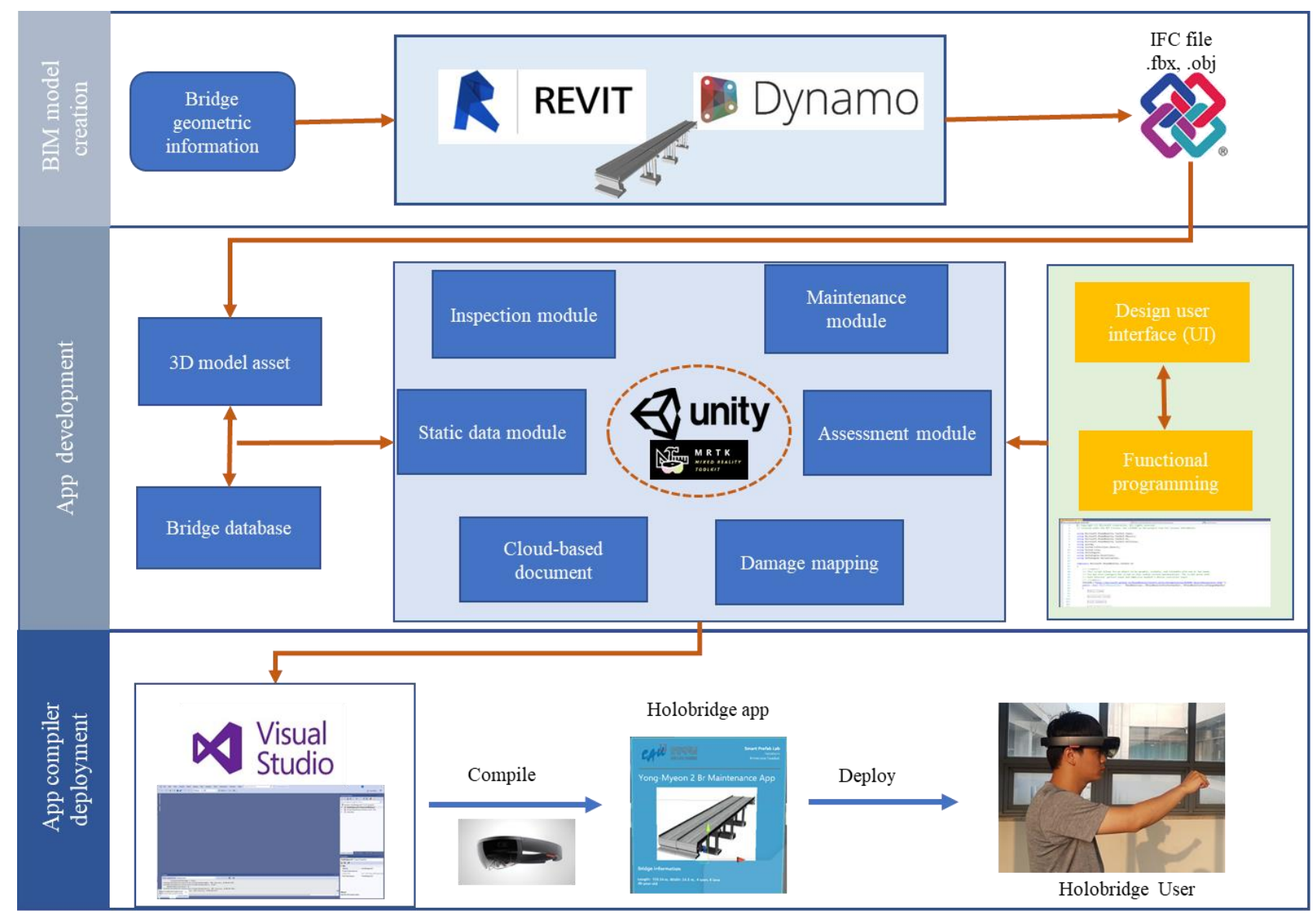

Figure 2. The workflow of HoloBridge application development

\subsection{Implementation}

The case study bridge is a PSC girder bridge built in 2001, 120-meter length with four spans as seen in Figure 3. General, principal, and special inspection jobs for the bridge have been conducted with modern technologies using a drone, laser scanning, and GPR data. The most common damages are crackings and spalling on the piers, girders, and bottom slab surfaces. The inspection data have been stored under 2Dbased forms such as AutoCAD damage drawings, inspection photos, and reports. The bridge was selected because the current management system has limitations in digitising and analysing damage information during the damage development process. These data are discrete and not linked between the current and previous results to monitor the damage development, especially for crack propagation. In order to systematically manage the inspection records, the bridge information model has been defined. This is a single-source data model in which the inspection data of bridge structures have been integrated with $3 \mathrm{D}$ information element models. 


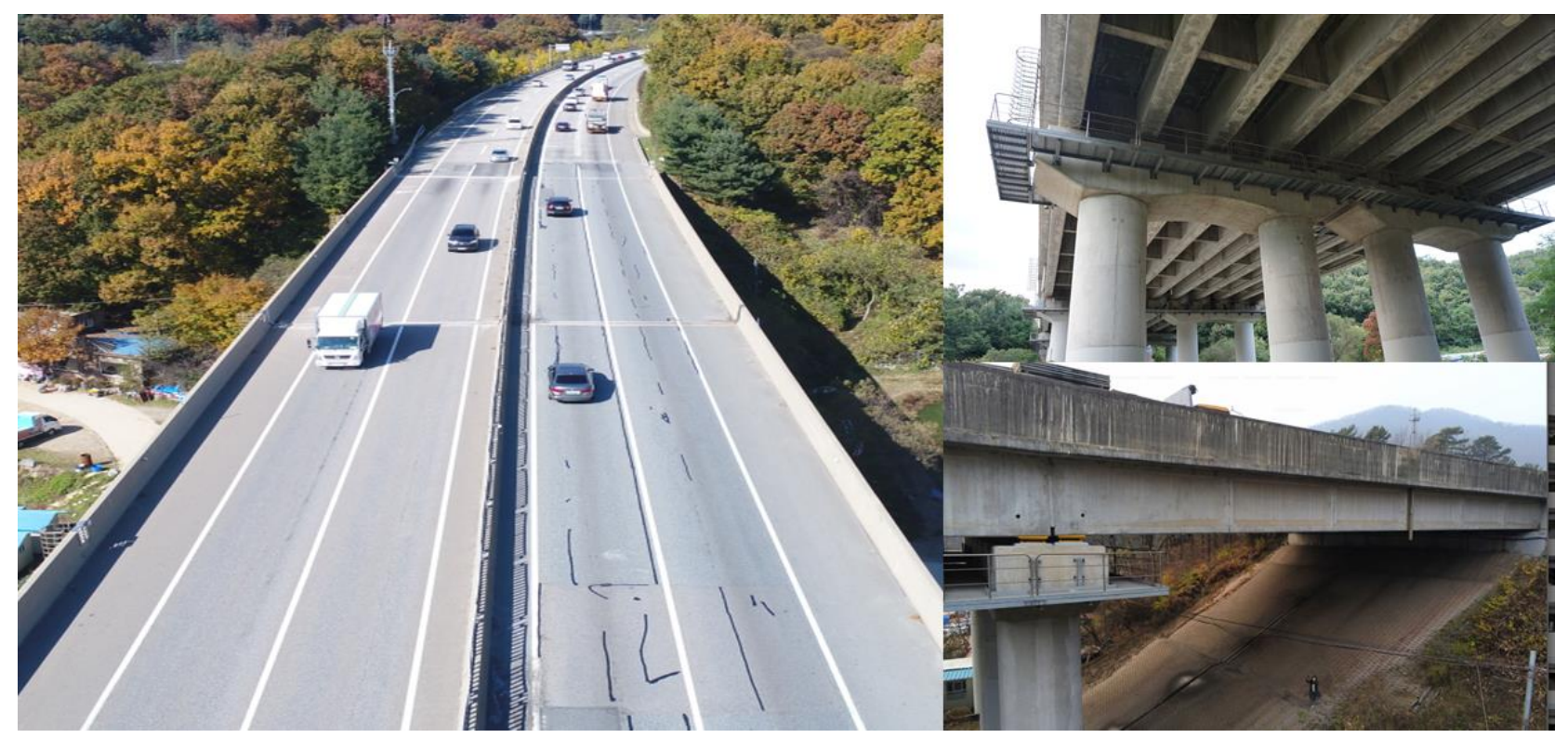

Figure 3. Case study bridge

\section{BIM-based bridge inspection and maintenance}

\subsection{Bridge inventory system}

The structural components are categorised and put into an inventory system based on their roles in the bridge system. Generally, the inventory includes the superstructures (e.g., slabs, girders, cross beams, barriers, bearings, expansion joints) and the substructures (e.g., bridge piers, abutments). The category system enables the identification of structural elements by using specific identifications (hereafter, ID), following a specified naming convention, and creates a systematic database. According to the ID definition, the $3 \mathrm{D}$ information model of bridge structures is generated by object-oriented modelling. The entire bridge model will be assembled by all elements' ID with coordinate and constraint data from bridge alignment. Figure 4 presents the inventory system with a detailed hierarchical category and ID naming convention.

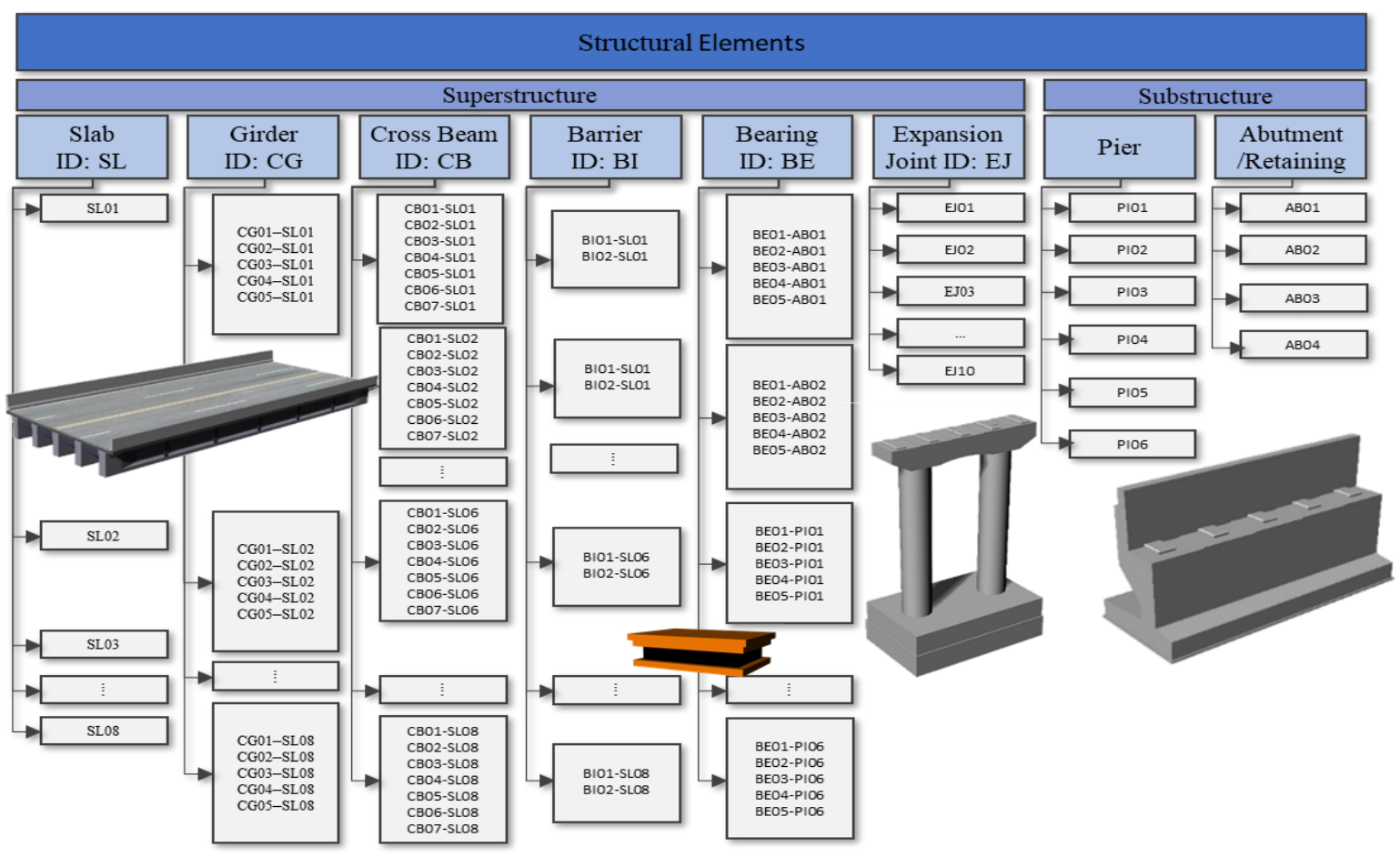


Figure 4. Inventory system and ID definition

\subsection{Model authoring}

The creation of the BrIM model is an essential task in the stage of BIM-based system establishment. According to the inspection and maintenance purpose, the BrIM model has been developed from 2D CAD drawings in the level of development (LOD) 300. The model are significantly featured by: structure recognition, relationship modelling, and object-based parametric modelling. Structure recognition has a function to label the queried bridge components followed by the inventory system and ID definition. Relationship modeling establishes the topological relationship of bridge components. The object-based parametric modelling aims to generate a 3D digital representation of bridge components by the geometric parameters and modelling algorithms. A modelling algorithm is a mathematical calculation between geometric constraints and dimensions that automatically changes the shape of the model when the dimension value is modified. Parametric modeling method is selected as the authoring method due to its flexibility, speed, and accuracy when using parametric features for model development. Figure 5 illustrates a flowchart of bridge model authoring. There are four steps to develop a parametric bridge model. First, the bridge element model needs to be defined from the inventory system with ID naming convention. Second, this step requires identifying the geometric and alignment parameter of each element. For instance, a bridge pier model comprises foundation, column, and pier cap with the main geometric parameters such as lengths, widths, heights, radiuses, the positions, orientations, and constraints of the alignment parameters. Third, the object models are built based on the geometric and alignment algorithm. The geometric algorithm is the process of creating the geometric data of an element model from the primitive shape such as curve, surface, solid in the Euclidean three-dimensional space. The alignment algorithm is created from the coordinated system and orientation vector from the whole model structure and constraints of element objects. Similar modelling techniques are applied to model all of the elements, such as abutments, girders, slabs, and barriers. Finally, bridge substructures and superstructures models are placed in accordance with the 3D alignment-based parameters of the entire bridge model.

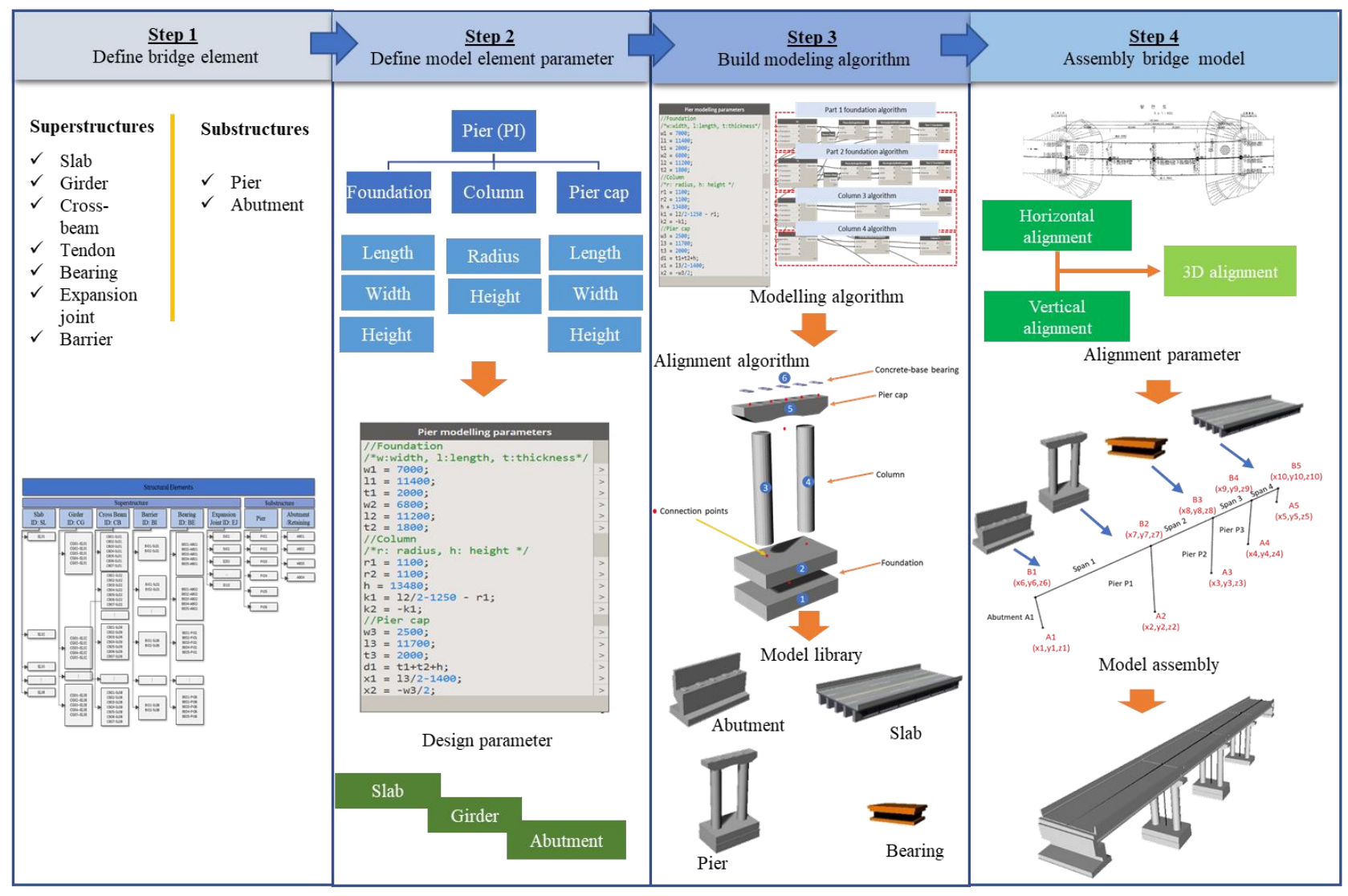


Figure 5. Model authoring process

Figure 6 explains the process of converting the 3D foundation model from BIM platform to HoloBridge application. In this research, the bridge model from Dynamo is exported to Revit to finalize BIM models with the attribute and as-built information. From Revit, the bridge model is converted to the exchangeable 3D format, such as IFC and FBX. In Unity 2019.3, a cross-platform game engine, the application has been developed with the programming of functional modules for inspection works. After the bridge model has been established, the application database is constructed with the systematic structure and data integration architecture.

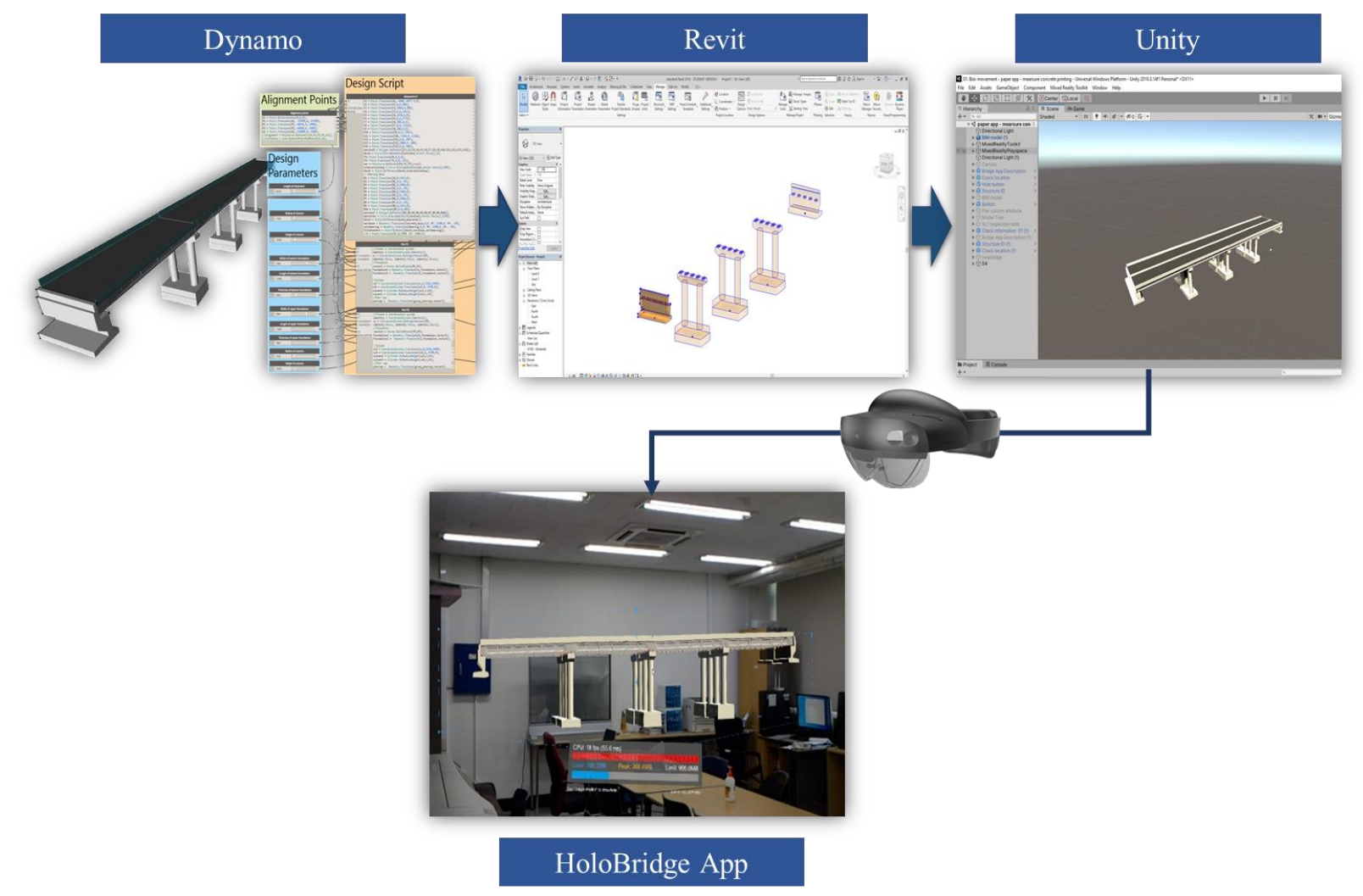

Figure 6. Importing model to application

\subsection{Database system}

The application database has three main parts: inspection and maintenance data storage, 3D BIM foundation model, and data integration architecture. The inspection and maintenance data are commonly managed by various reports. The data accumulation and curation can be efficiently organized by BIM based and MR platform features. The BIM-based bridge database is established by integrating the corresponding data into the specific 3D structure model based on systematic classification from the inventory system. A structure element data has three main parts in the database management system: 3D model, model attribute, and model archive. In the 3D model environment, users can easily interact with the structure elements using ID identification since they have been modelled by object-oriented techniques. Therefore, the 3D model inventory can systematically be accessed to extract and integrate data. Figure 7 illustrates an example of the schematic information system of the bridge slab that can be standardized for information management of other structural elements. The model attribute part contains general information in terms of the physical properties such as geometric, material properties, ID, and location. It is the original data and extension part of the 3D model for network-level maintenance works. Besides, each element has its archive data list, which consists of all information for bridge inspection and maintenance requirements such as as-built information, inspection sheets, damage properties, repair 
manual, and history. During the bridge operation phase, data is accumulated in the archive data by the defined code system described in Section 4.4.

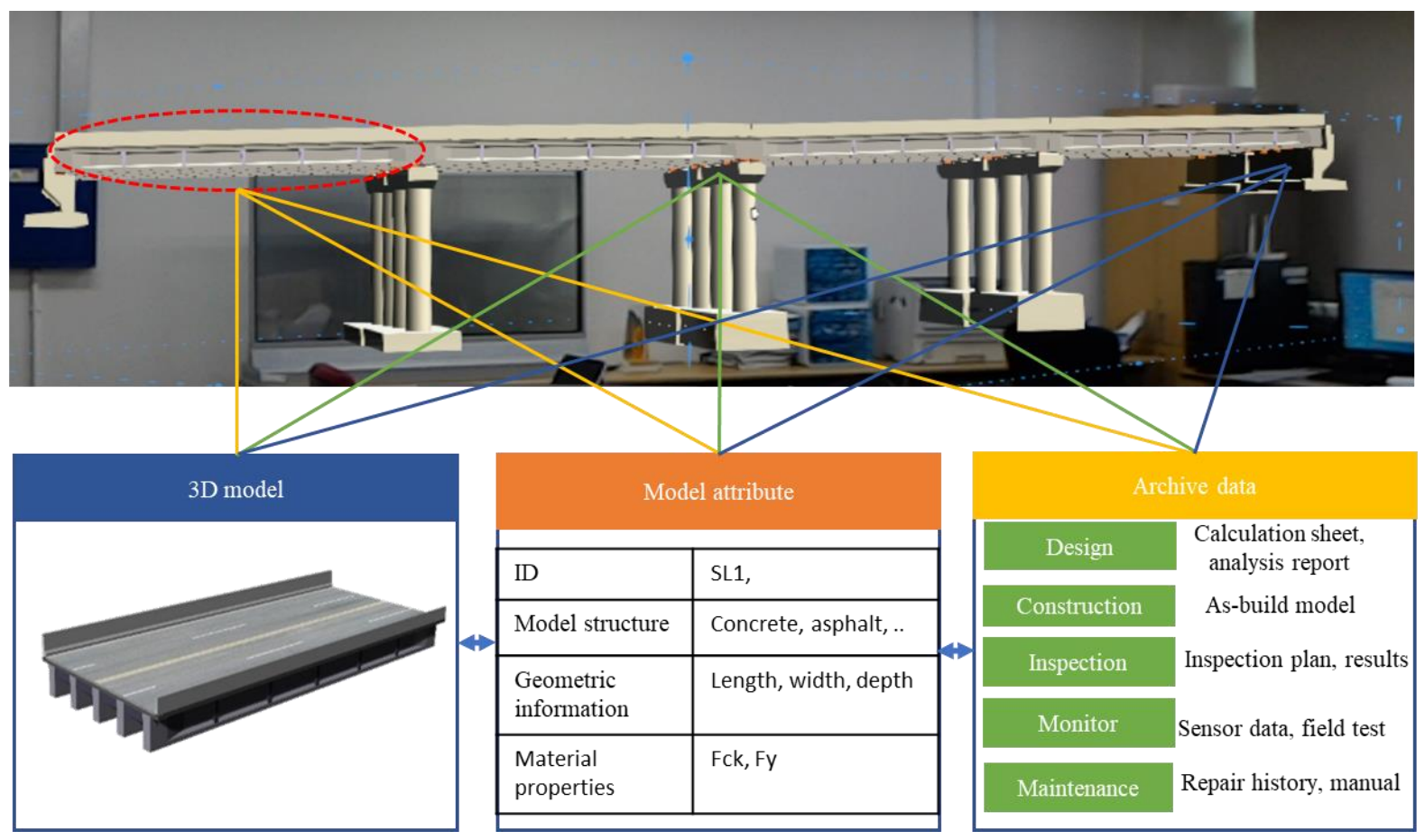

Figure 7: The schematic information system

\subsection{Documentation and damage code system}

According to the guideline of bridge inspection and maintenance practices, a vast amount of inspected data from many sources has been accumulated during the service life. Nonetheless, the unclassified document is not available for inspectors who are to develop a deterioration model and monitor damage development based on the field inspection. In order to solve this problem, the document and damage code system was proposed, as shown in Figure 8 (Shim et al., 2019). For the document identification, class 01 is bridge name ID, and class 02 complies with the inventory system. Class 03 and 04 are the type and number of documents, respectively. From document to damage identification, class 05 and 06 are added to define damage and date of inspection. In the inspection documentation, the inspector uses the naming convention to quickly identify the damages with the history which is essential information for the maintenance task. Subsequently, the document of archive data can be linked to the model attribute document through the proposed code system and element ID. When this data system is used for whole bridges in a country, digital twin models for bridge members to demonstrate damage history can be built and utilized for future performance prediction. 


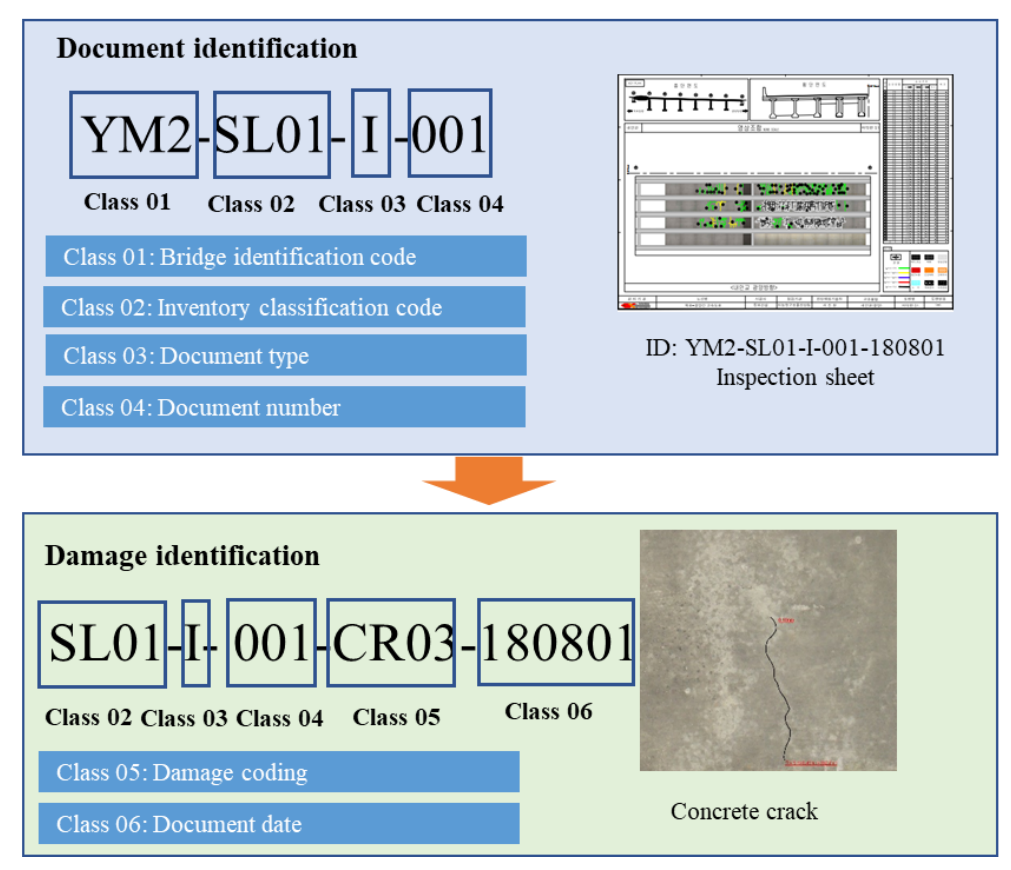

\begin{tabular}{|l|c|}
\hline \multicolumn{2}{|c|}{ Class 03 } \\
\hline Document type & Code \\
\hline Design & $\mathrm{D}$ \\
\hline Inspection & $\mathrm{I}$ \\
\hline Maintenance & $\mathrm{M}$ \\
\hline Construction & $\mathrm{C}$ \\
\hline
\end{tabular}

\begin{tabular}{|l|c|}
\multicolumn{2}{|c|}{ Class 05 } \\
\hline Damage type & Code \\
\hline Crack & CR \\
\hline Spalling & SP \\
\hline Delamination & DE \\
\hline Honeycombing & HO \\
\hline Leaching & LE \\
\hline
\end{tabular}

Figure 8: Document and damage coding definition

\section{Prototype for implementing the features of application}

\subsection{Bridge inspection module}

Enhancing the interpretation, analysis, and evaluation is the main aim for visualising damage records in MR environment. The user with Hololens can walk around the virtual bridge and intuitively interact inspection database at defect locations. The damage is visualised with the properties such as location, dimension, history, and causes. The bridge management agency categorises the damage based on bridge structure itself, such as the slab's damages, abutment, pier, and girder. The common types of bridge defects are cracking, spalling, scaling, corrosion, leaching, and delamination. Some defects can be detected by visual inspection (e.g., cracks, spalling, scaling), while others require the additional tool such as using GPR. Figure 9 presents the system architecture of the inspection module. The data is extracted from the inspection report and then embedded into the BIM element model. An inspection BIM model is a federated model with the defect database attached and located on bridge element surfaces.

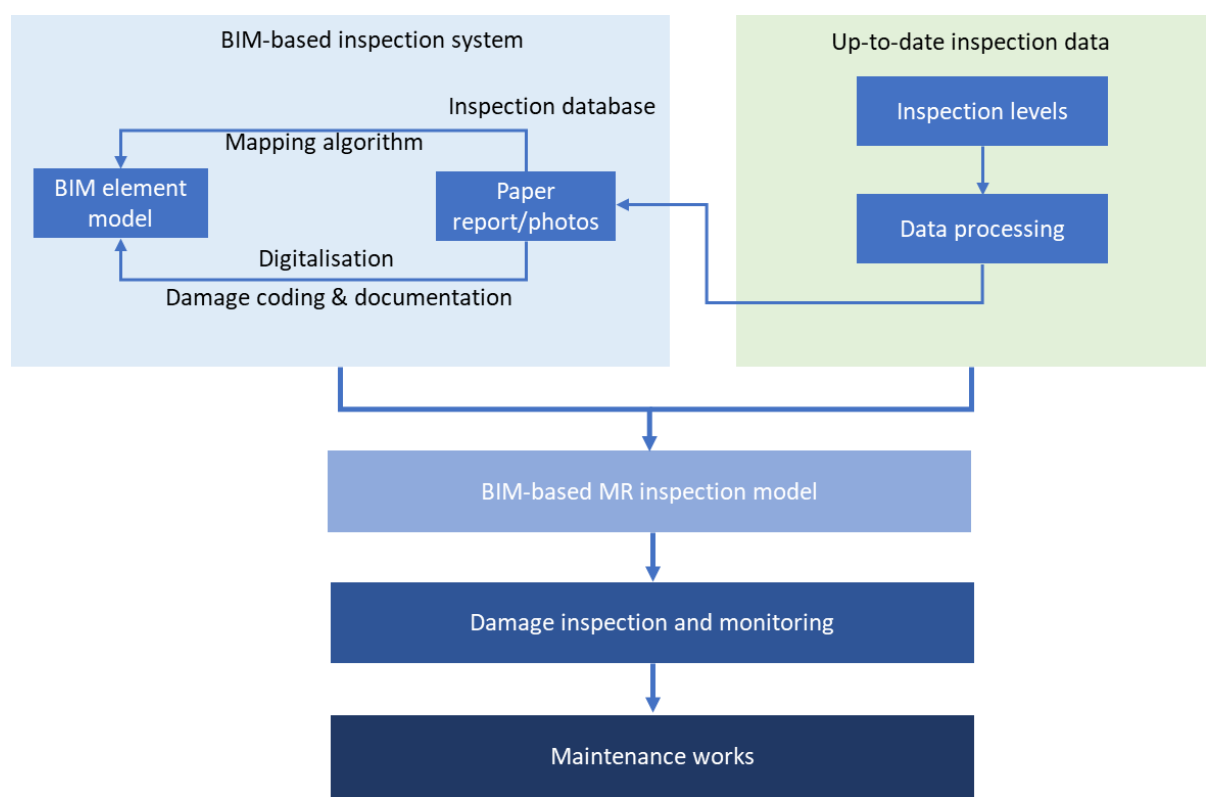


Figure 9. System architecture of inspection module

In the MR space, BIM-based MR inspection model is established. On 3D model element surfaces, the damage can be managed through the location-based algorithm. Each damage position has been marked by an icon, which is linked with the damage database for observing and managing the damage development. The damage management process has two main steps, which are damage inspection and monitoring. Damage inspection is the process of checking the damage on BIM surface model, which is mapped and linked with the relevant information for describing defects in terms of type, shape, dimension, and position. Condition state, cause, and influence factors will be defined in the damage monitoring process. Overall, the parameters of damage properties and monitoring are required for effectively managing damage development. Figure 10 shows an example of monitoring crack development at a damage position. The crack information contains ID, type, crack metric with width and length, condition state, cause, influence factors, and crack history.

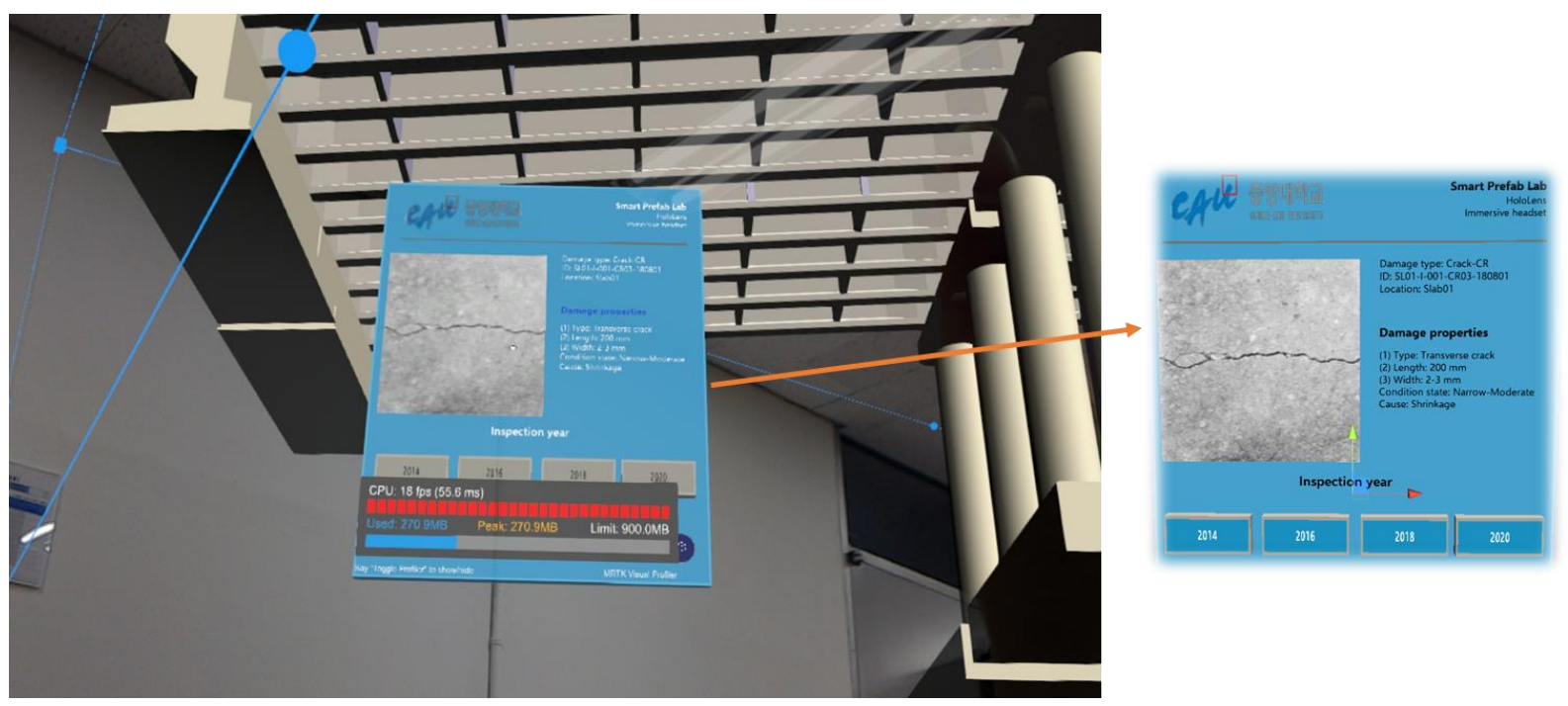

Figure 10. Damage visualization

\subsection{Damage mapping module}

The mapping module is developed for overlapping inspection photos with the $3 \mathrm{D}$ element model to provide a picture of an existing condition. The concept of mapping defect images onto BIM models has been done by Hüthwohl et al., (2018) to create an integrated inspection model element. In this case study, the mapped model is a federated model to enrich information for inspection works. The element model is divided into observable surfaces, including top, lateral and bottom surface to overlap information. In the MR working space, inspectors can check the damage information on the surface of the bridge elements model. Importantly, the inspection data can be stored in the element model during the operation phase. It is a single-source information for monitoring damage development and developing a deterioration model. Figure 11 provides an example of mapping GPR data on the top surface of the slab to evaluate slab thickness, measurement of the concrete cover thickness, and locating rebar. 


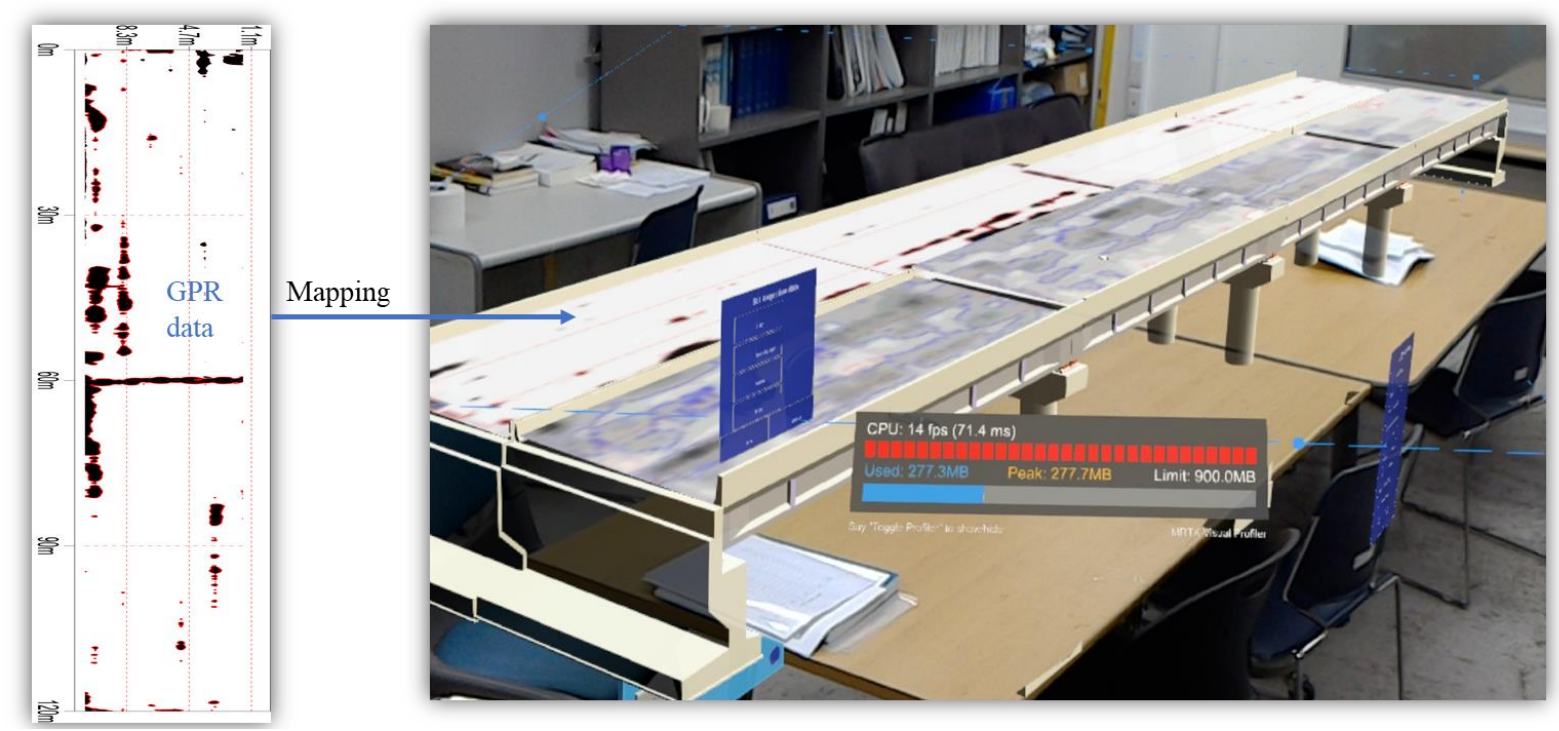

Figure 11. GPR image mapping

Figure 12 explains the integration of inspected bridge slab data with BIM to create a slab inspection model. The inspection data is then mapped on each span. The bottom surface can be overlapped with 3D scan model and the inspection photos. With GPR data for upper surface and damage records of the lower surface, more reliable assessment can be delivered.

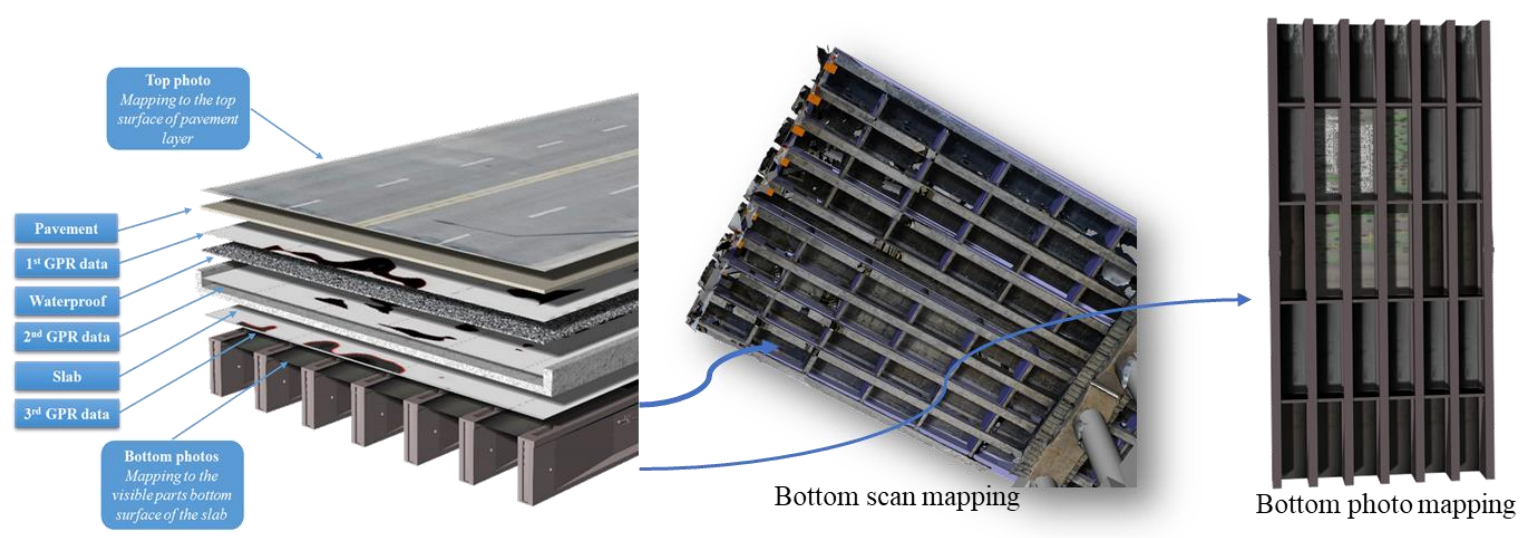

Figure 12. BIM-based bridge slab inspection model

The 3D scanned model bridge can be visualised in the application along with BIM and inspection data. Inspectors can accurately and quickly capture the detailed geometric surfaces of bridge structures with damages by laser scanning and drone filming. The 3D scanned model is readily applicable to overlap with bridge BIM model to create a geometric digital twin. Figure 13 shows the result of visualising a 3Dscanned model in the MR space. The overlapping between BIM and 3D scanned model enables the inspectors to identify the defect location based on the reference BIM model. Furthermore, the geometric digital twin model can be used to develop a maintenance plan by integrating the current condition of the 3D scanned layer with the design information within BIM. 


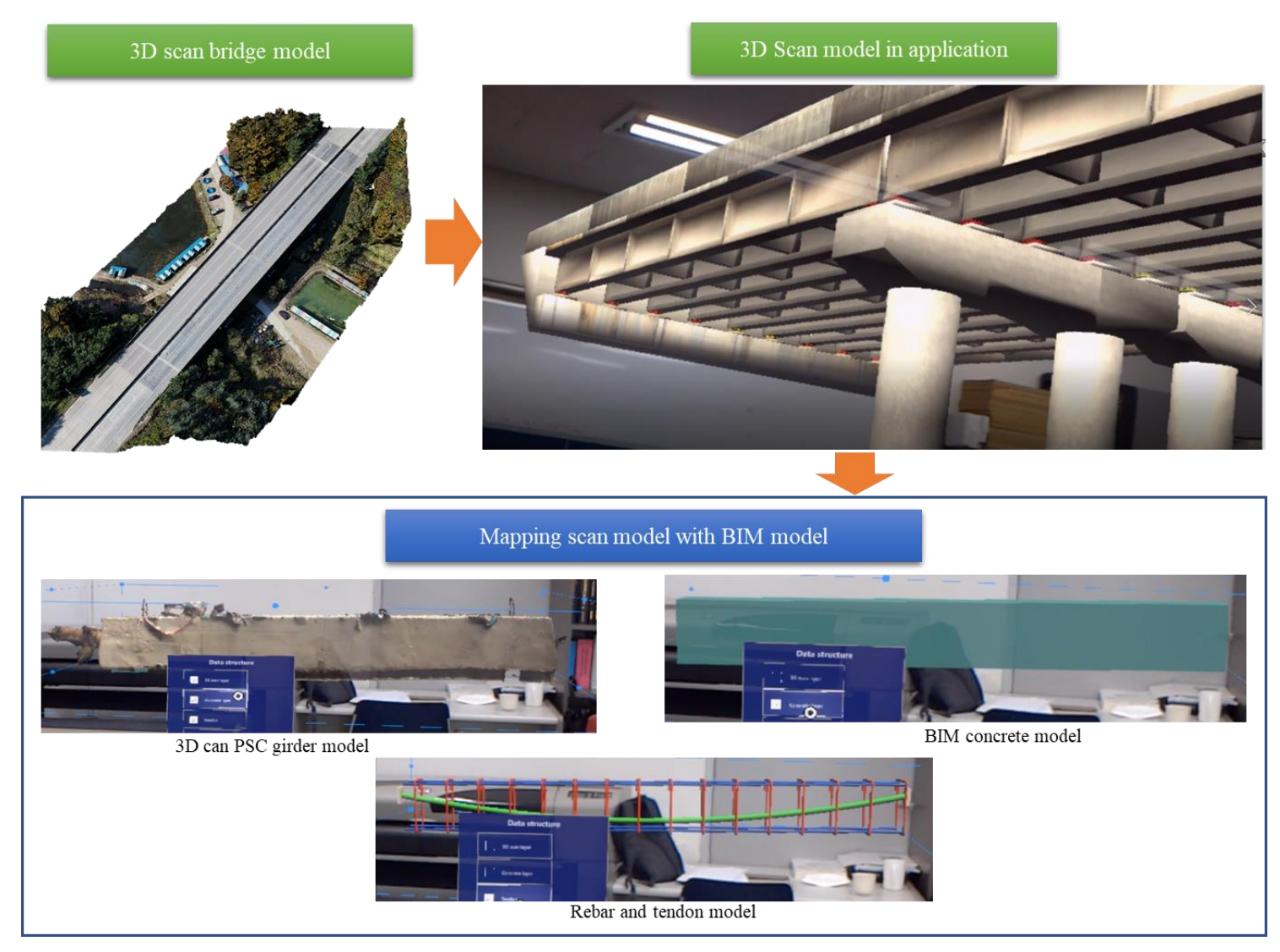

Figure 13. Mapping scan module

\subsection{Bridge evaluation and maintenance module}

Based on the damage evaluation results, bridge structures have been classified as critical and non-critical. The condition rating of each element is defined by a deterioration model, including the field inspection result and the quantity analysis of damages' history. To highlight the dangerous structures, the colour condition rating module is developed. The bridge element model can be shown in different colours (see Figure 14). The rating system defines four levels, i.e., good, fair, poor, and severe, corresponding to blue, green, yellow, and red colour codes. The pier column in yellow colour (Figure 14) shows that it is in the poor condition, and needs to be repaired. The green structures are in good condition; and the red girder is in severe condition and required replacement. As a result, the inspectors can identify the structures in dangerous conditions to perform maintenance actions. The maintenance database such as maintenance quantity and repair history can be linked with each element model and inspection data.

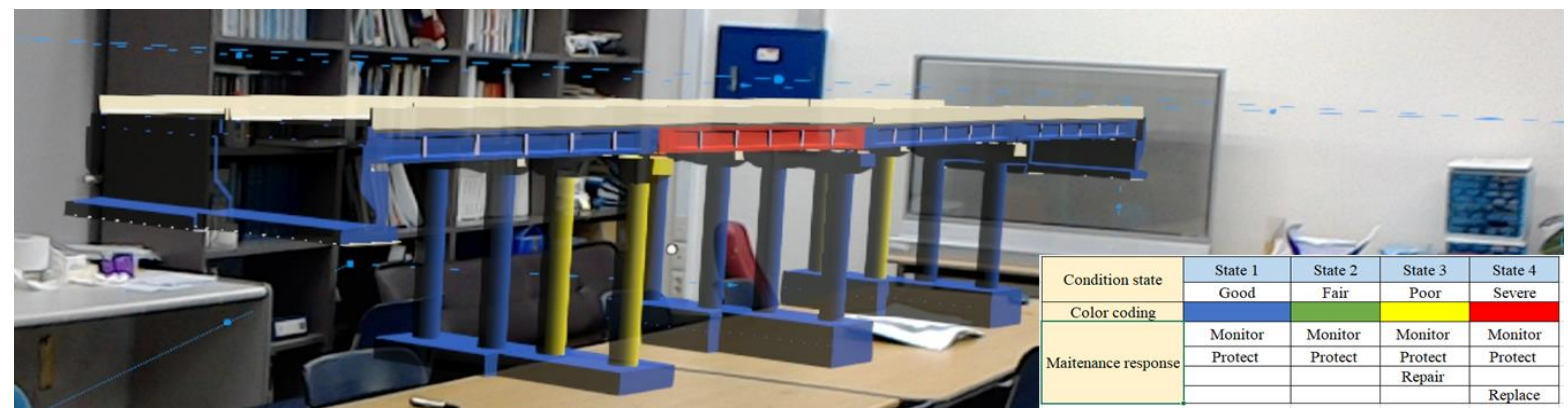

Figure 14. Condition rating visualisation of bridge structure 


\section{Conclusions and future works}

This research contributes to the body of knowledge by demonstrating the potential value of integrating MR into BIM workflow for bridge inspection and maintenance. The concept of BIM-based bridge inspection is developed from theory to application. The development process has two main parts: creating the database and programming of the functional modules. The application database has three essential components: a well-organised foundation BIM model, inspection and maintenance information, and data integration architecture. The functional modules include inspection, evaluation, and damage mapping modules. The findings from the pilot implementation include:

1. Through the proposed framework, the inspection information management has been improved by the BIM-based system. It provides the systematic linking of inspection records with BIM element models in the operation phase. Moreover, the method is centralizing all the inspection and maintenance in a single bridge BIM model. This model is overcoming the discrete of current 2D-based form information management.

2. In the MR working space, the Holobridge application included BIM-based systematic data has improved the interpretation, visualization and collaboration of inspection and maintenance information because the information is more intuitively interactive in real-time simulation.

3. The inspection and maintenance tasks are significantly enhanced and facilitated by using a federated information model in MR wherein the damage is mapped with a 3D BIM foundation model during the whole life cycle of a bridge.

4. The updated inspection database could be systematically managed through BIM system, and the proposed code system enables monitoring of damage development and creates a deterioration model efficiently.

This research has some limitations related to the direct connection between the application with on-site inspection works. Additionally, it is necessary to have an optimized algorithm for big data processing in the whole life cycle of bridge. Therefore, future research will be extended to develop a module for onsite inspection using Hololens based on spatial anchors algorithm. It will be connected with the inspection database in the office. A module for cloud-based service using Microsoft Azure will be developed to store inspection data. Finally, static digital twin models for bridge members can be established by this application.

\section{Acknowledgements}

This is a substantially extended and enhanced version of the paper presented at The 20th International Conference on Construction Applications of Virtual Reality (CONVR 2020). We would like to acknowledge the editorial contributions of Professor Nashwan Dawood and Dr. Farzad Rahimian of Teesside University in the publication of this paper.

\section{Funding}

This research was conducted with the support of the "National R\&D Project for Smart Construction Technology (No.21SMIP-A158708-02)" funded by the Korea Agency for Infrastructure Technology Advancement under the Ministry of Land, Infrastructure and Transport, and managed by the Korea Expressway Corporation. 


\section{Reference}

Abdelkader, E.M., 2021, "On the hybridization of pre-trained deep learning and differential evolution algorithms for semantic crack detection and recognition in ensemble of infrastructures", Smart and Sustainable Built Environment, doi: 10.1108/SASBE-01-2021-0010

Al-Adhami, M., Wu, S. and Ma, L., (2019), "Extended Reality Approach for Construction Quality Control", Proceedings of CIB World Building Congress 2019, Hong Kong.

Al-Shalabi, F. A., Turkan, Y., and Laflamme, S., (2015), "BrIM implementation for documentation of bridge condition for inspection", Proceedings of the Canadian Society for Civil Engineering 5th International/11th Construction Specialty Conference, Vancouver, Canada, pp. 7-10.

Chalhoub, J., and Ayer, S. K. (2018), "Using Mixed Reality for electrical construction design communication", Automation in Construction, Vol 86, pp.1-10, doi: 10.1016/j.autcon.2017.10.028.

Dabous, S. A., \& Feroz, S. (2020), "Condition monitoring of bridges with non-contact testing technologies", Automation in Construction, Vol 116, doi: 10.1016/j.autcon.2020.103224

Davidson, J., Fowler, J., Pantazis, C., Sannino, M., Walker, J., Sheikhkhoshkar, M. and Rahimian, F.P., 2020, "Integration of VR with BIM to facilitate real-time creation of bill of quantities during the design phase: A proof of concept study", Frontiers of Engineering Management, 7(3), pp.396-403, doi: 10.1007/s42524-019-0039-y

Demian, P., and Walters, D. (2014), "The advantages of information management through building information modelling", Construction Management and Economics, Vol. 32 No 12, pp. 1153-1165, doi: 10.1080/01446193.2013.777754.

Dunston, P. S., and Wang, X. (2005), "Mixed reality-based visualization interfaces for architecture, engineering, and construction industry", Journal of Construction Engineering and Management, Vol. 131 No 12, pp. 1301-1309, doi: 10.1061/(ASCE)0733-9364(2005)131:12(1301).

Eastman, C. M., Eastman, C., Teicholz, P., Sacks, R., and Liston, K. (2011), BIM handbook: A guide to building information modeling for owners, managers, designers, engineers and contractors, John Wiley \& Sons.

El Ammari, K. and Hammad, A., (2019), "Remote interactive collaboration in facilities management using BIM-based mixed reality", Automation in Construction, Vol.107, doi: 10.1016/j.autcon.2019.102940.

Elghaish, F., Matarneh, S., Talebi, S., Kagioglou, M., Hosseini, M. R., \& Abrishami, S. (2020), "Toward digitalization in the construction industry with immersive and drones technologies: a critical literature review", Smart and Sustainable Built Environment, doi: 10.1108/SASBE-06-2020-0077

Feng, C.W. and Chen, C.W., (2019), "Using BIM and MR to improve the process of job site construction and inspection", WIT Transactions on The Built Environment, Vol.192, pp. 21-32, doi: 0.2495/BIM190031.

Hamzeh, F., Abou-Ibrahim, H., Daou, A., Faloughi, M. and Kawwa, N., (2019), "3D visualization techniques in the AEC industry: the possible uses of holography", ITcon, Vol. 24, pp. 239-255.

Hüthwohl, P., Brilakis, I., Borrmann, A. and Sacks, R., (2018), "Integrating RC bridge defect information into BIM models", Journal of Computing in Civil Engineering, Vol 32 No 3, doi: 10.1061/(ASCE)CP.1943-5487.0000744.

Karaaslan, E., Bagci, U. and Catbas, F. N. (2019), "Artificial Intelligence Assisted Infrastructure Assessment using Mixed Reality Systems", Transportation Research Record, Vol. 2673 No. 12, pp. 413-424, doi: 10.1177/0361198119839988. 
Mansuri, L.E. and Patel, D.A., 2021, "Artificial intelligence-based automatic visual inspection system for built heritage", Smart and Sustainable Built Environment, doi: 10.1108/SASBE-09-2020-0139

Mascareñas, D.D., Ballor, J.P., McClain, O.L., Mellor, M.A., Shen, C.Y., Bleck, B., Morales, J., Yeong, L.M.R., Narushof, B., Shelton, P. and Martinez, E., (2020), "Augmented reality for next generation infrastructure inspections", Structural Health Monitoring, doi: 10.1177/1475921720953846.

McGuire, B., Atadero, R., Clevenger, C. and Ozbek, M., (2016), "Bridge information modeling for inspection and evaluation", Journal of Bridge Engineering, Vol. 21 No. 4, doi: 10.1061/ (ASCE)BE.1943-5592.0000850.

Moreu, F., Bleck, B., Vemuganti, S., Rogers, D. and Mascarenas, D., (2017), "Augmented reality tools for enhanced structural inspection", Proceeding of 11th Int. Workshop on Structural Health Monitoring, Stanford, United State, doi: 10.12783/shm2017/14221.

Nili, M. H., Taghaddos, H., \& Zahraie, B. (2021), "Integrating discrete event simulation and genetic algorithm optimization for bridge maintenance planning". Automation in Construction, Vol 122, doi: $\underline{10.1016 / j . a u t c o n .2020 .103513}$

Omer, M., Margetts, L., Hadi Mosleh, M., Hewitt, S. and Parwaiz, M., (2019), "Use of gaming technology to bring bridge inspection to the office", Structure and Infrastructure Engineering, Vol 15 No. 10, pp. 1292-1307, doi: 10.1080/15732479.2019.1615962.

Prabhakaran, A., Mahamadu, A.M., Mahdjoubi, L. and Manu, P., (2020), "An approach for integrating mixed reality into BIM for early stage design coordination", Proceeding of MATEC Web of Conferences, Vol. 312, doi:10.1051/matecconf/202031204001.

Riexinger, G., Kluth, A., Olbrich, M., Braun, J.D. and Bauernhansl, T., (2018), "Mixed Reality for onsite self-instruction and self-inspection with Building Information Models", Proceeding of 51st CIRP Conference on Manufacturing Systems, Vol. 72, pp.1124-1129, doi: 10.1016/j.procir.2018.03.160.

Rokhsaritalemi, S., Sadeghi-Niaraki, A. and Choi, S.M., (2020), "A review on mixed reality: current trends, challenges and prospects", Applied Sciences, Vol. 10 No. 2, doi: 10.3390/app10020636.

S Sacks, R., Kedar, A., Borrmann, A., Ma, L., Brilakis, I., Hüthwohl, P., Daum, S., Kattel, U., Yosef, R., Liebich, T. and Barutcu, B.E., (2018), "SeeBridge as next generation bridge inspection: overview, information delivery manual and model view definition", Automation in Construction, Vol. 90, pp. 134-145, doi: 10.1016/j.autcon.2018.02.033.

Salamak, M. and Januszka, M., (2018), "BrIM bridge inspections in the context of Industry 4.0 trends", Proceedings of the 9th International Conference on Bridge Maintenance, Safety and Management, IABMAS, Melbourne, Australia.

Sheikhkhoshkar, M., Rahimian, F.P., Kaveh, M.H., Hosseini, M.R. and Edwards, D.J., 2019, "Automated planning of concrete joint layouts with 4D-BIM", Automation in construction, Vol. 107, doi: 10.1016/j.autcon.2019.102943

Shim, C.S., Dang, N.S., Lon, S. and Jeon, C.H., (2019), "Development of a bridge maintenance system for prestressed concrete bridges using 3D digital twin model", Structure and Infrastructure Engineering, Vol. 15 No. 10, pp. 1319-1332, doi: 10.1080/15732479.2019.1620789.

Shim, C.S., Lee, K.M., Kang, L.S., Hwang, J. and Kim, Y.,( 2012), "Three-dimensional information model-based bridge engineering in Korea", Structural Engineering International, Vol. 22 No. 1, pp. 8-13, doi: 10.2749/101686612X13216060212834. 
Shim, C.S., Kang, H.R., Dang, N.S. and Lee, D.K., (2017), "Development of BIM-based bridge maintenance system for cable-stayed bridges", Smart Structures and Systems, Vol. 20 No. 6, pp. 697-708, doi: 10.12989/sss.2017.20.6.697. 